\title{
Research on the Experience Value of the Communication and Consumption of Traditional Handicraft in the New Media Era
}

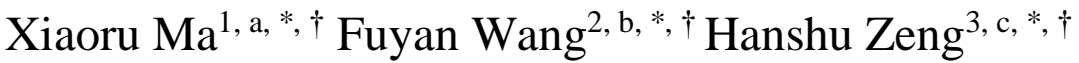 \\ ${ }^{1}$ University of Nottingham Ningbo China, Ningbo, China \\ ${ }^{2}$ Northeast Forestry University, Harbin, China \\ ${ }^{3}$ Changsha University of Science and Technology, Changsha, China \\ ${ }^{*}$ Corresponding author.Email: ${ }^{a}$ hiyxm2@nottingham.edu.cn, ${ }^{b}$ wfy2018@nefu.edu.cn, ${ }^{c} 1063095087 @ q q . c o m$ \\ ${ }^{\dagger}$ These authors contributed equally.
}

\begin{abstract}
With the development of the times and science and technique, new media such as Tik Tok has become an effective way of cultural communication. They have a significant impact on disseminating intangible cultural heritage. As one of the important components of intangible cultural heritage, traditional handicraft is also faced with many opportunities and challenges in the new media era. This paper mainly adopts a case study and questionnaire survey to discuss the influence and significance of Tik Tok's participation in disseminating intangible cultural heritage, including bronze carving skills, Qiao family handmade leather Art, and Miao silver jewelry manual forging technique. The public experience value also analyzes the different forms and connotations from aesthetic experience value, emotional experience value, functional experience value, and cultural value identity. The study found that the inheritors of intangible cultural heritage are changing to "opinion leaders" of new media, which would help the public to have a more comprehensive understanding of the rich connotation and multiple values of intangible cultural heritage. At the same time, the diversity of inheritors in the process of new media display and marketing is more conducive to thickening the public's online consumption experience value.
\end{abstract}

Keywords: Experience value, traditional handicraft, intangible cultural heritage, new media.

\section{INTRODUCTION}

Intangible cultural heritage is an important cultural resource. With the social changes and the development of new media techniques, making traditional culture play a positive role in the contemporary era and become an organic part of people's daily lives, which has also become a hot topic in recent years.

Short video platforms, such as Tik Tok, have begun to play a vital role in disseminating intangible cultural heritage. According to data released by Tik Tok, as of April 2019, more than $88 \%$ of all national representative intangible cultural heritages have been disseminated on the Tik Tok platform and have generated more than 24 million videos and over 106.5 billion plays. Some scholars proposed that short video platforms were characterized by a large number of communications, fast and wide dissemination [1]. As three-dimensional and multi-dimensional information carriers, short video platforms played an important role in promoting the technical dissemination and innovative promotion of intangible cultural heritage [2]. And the communication effect gave users an immersive experience and provided a new revenue model for inheritors [3]. With the arrival of $5 \mathrm{G}$ era, the content logic of short videos would change dramatically, entering a stage where PGC (professionally produced content) was the main focus. Short video platforms would integrate display, dissemination, socialization, and sales, not only making intangible cultural heritages "live" but also making them "fire" [4]. However, in order to cater to the audience, there is also a tendency to over-commercialize and entertain the content and insufficient protection of ethnic, cultural symbols in the process of dissemination [5], and the quality of the videos varies due to differences in the filming and editing techniques of the inheritors. 
The research on experience value has attracted more and more attention in recent years. The experience value is defined differently in different subject areas. The economic field refers to the customer's perception of the experience after consumption, which must be experienced in person to be realised [6]. In management, it has been argued that experience value is a subjective emotion that an experience can bring to the consumer and is shaped by value judgments [7]. It refers to the interaction and involvement, emotional resonance, and value recognition brought by the audience during and after the consumption of a product or content [8]. According to some related research on experiential value, the block selection of cognitive, contextual, and economic value indicates self-explicit participation needs of intangible cultural heritage experiencers. In contrast, the living and heritage values are new experiential values of intangible cultural heritage [9]. In the new media era, user experience and interaction are important elements for producers to measure the value of their products. As the study of audience experience value is gaining more and more attention, the social network perspective (interaction) and co-creation value perspective (co-creation of user experience) are now the mainstream views in experience value research.

This paper will take Tik Tok as an example to discuss some effects of new media communication on disseminating and innovative inheritance of intangible cultural heritage. Meanwhile, it will narrate and explain specific situations of consumption and value experience from the perspective of the receiving crowd.

The main method of this paper is the case study. We tried to better understand the phenomenon of Tik Tok users' preferences toward commodities of traditional Chinese handcraft intangible cultural heritage and related experience value through a questionnaire survey. There are 17 questions in the questionnaire, which consists of fundamental information of survey object, Likert scale, and one open-ended question for potential answers. $72.86 \%$ of participants are undergraduate students from 19 to 30 years old. We initially found that contemporary young people hold a positive attitude towards the new media communication of intangible cultural heritage, but many people do not fully understand intangible cultural heritage. It can be seen that the communication methods and strategies need to be further improved.

\section{CULTURAL VALUE IDENTITY: A CASE OF BRONZE CARVING SKILLS}

Bingren Zhu, is one of the most famous and representative Chinese national bronze carving skills' inheritors and a master of Chinese arts and crafts. He has made 511 videos and has been followed by nearly 600,000 people on Tik Tok. He has never done a live broadcast on Tik Tok so far, merely issued short videos per week or even per month, mainly about three contents. This part will take Bingren Zhu' s ID on Tik Tok as an example to analyze the value identification of national intangible cultural heritages.

Firstly, the Large majority of his videos related to the output of copper cultural relics and his well-known architectural pieces, such as the bronze body of Leifeng Tower in Hangzhou, the golden roof of mountain E' mei in Sichuan. In the comments section of these videos, followers commented that he was a genuine master and showed their great fondness and respect.

Secondly, several videos were produced to introduce his talented personal skills, such as the marvelous molten copper hand and his calligraphic writing skills. Below these kinds of videos, the audience is much more likely to ask some skill-relevant questions, most of which could find the author' $s$ answers. Through these interactions, visitors could probably have easier access to get in touch with this intangible technical, cultural heritage, simultaneously may gain both knowledge and enjoyment from these videos. As Mei and Chen mentioned, this type of interactive participation could satisfy the curiosity of the audience and enhance their understanding of this traditional artistry [10]. In this way, a bridge was built between the superior intangible heritage and the mass, thus strengthening a sense of cultural identification and aesthetic value.

Thirdly, a small number of videos published by master Zhu regarded his own life experience and families. These videos show viewers an approachable image of him and give people a piece of information that this great master is a human being, which possibly reduce the distance between the master and ordinary people. A shorter distance gives the audience better access to mutual emotional experience value. From three different kinds of videos above, though it still seems strange that only three videos he topped at the beginning of his interface were liked more than 100,000 times, others merely obtained tens of likes, his followers are still increasing.

It is not hard to see that Zhu 's ID has been comparatively slow to increase in popularity, and most of his short videos have received few likes and comments. Meanwhile, the number of products sold on the platform is also very small compared to other products of intangible technical skills. Apart from the fact that these copper products are not sold through live streaming and are normally expensive, one of the more important reasons why his online shop seems not so popular is that the public does not have a high level of acceptance reflecting this national copper carving technique. The high level of bronze carving technique, the unwatchable and inaccessible production process make it more far from people's daily lives. Therefore, it is conceivable that even if such products were to go on 
air, to a large extent, they would not sell as well as other kinds of non-material cultural heritage like snail noodles or oil-paper umbrellas.

As a result, national-level or high-level intangible cultural heritage need probably to pay more attention to its protection and inheritance, while folk-level skills may be necessary to explore their commercial value. That is, different layers of heritage are likely to have diverse orientations towards their final aims. Consequently, as for the copper carving skill, it is probably better to direct its propaganda to safeguard and stronger value recognition as the primary goal, then secondly exploit and develop its relatively particular market. Thus, the heir becomes a significant centric factor in protecting this kind of technical intangible cultural heritage. As Zeng has mentioned, the representative bearers are the core of the heritage in China. This group is responsible for transmitting the core genes of the intangible cultural heritage in the form of outstanding traditional skills [11]. It is imperative to improve the apprenticeship system for inheritors and establish an appropriate scholarship system to stabilize the reserve pool of inheritors. For instance, it is probably necessary to carry out ethnic, cultural heritage activities in schools by utilizing the school education platform, leading to a more systematic heir training. In conclusion, high-level intangible technical, cultural heritages such as copper carving skills need more sense of identification from the mass, rather than merely conforming popular ways to sell and directly disseminate.

\section{FUNCTIONAL EXPERIENCE VALUE: QIAO FAMILY HANDMADE LEATHER ART}

The "Qiao Family Handmade Leather Art" is an intangible cultural heritage project in Yinchuan, Ningxia Hui Autonomous Region. The complex process of making handmade leather art includes 126 processes such as drawing, carving, striking and colouring, and takes nearly 30 days. As the third-generation inheritor of the project, Qiao Xue has created her own leather products company and created her own brand, "Master Qiao". At present, "Master Qiao" handmade leather products have elements of Ningxia such as Helan Mountains, rock paintings, deserts, and the Yellow River, as well as fashionable elements such as tassels and rivets, and through the combination of handcraft techniques and modern elements to produce leather products that meet the needs and aesthetics of modern people. The public gradually understands this intangible cultural heritage, and its leather products are exported overseas. They have led to the employment of hundreds of women and disabled people, with strong social benefits.
Qiao Xue uses big internet data to analyse user profiles, define product positioning, and develop leather products such as bags and belts which meet modern aesthetic needs. She also promotes and broadcasts live shows on the Tik Tok to open up the market so that the intangible cultural heritage can generate its functional experience value.

After market research, "Qiao's Handmade Leather Art" has both a traditional Chinese style and a bag shape that is in line with current trends, such as round bags and square bags, etc. After the launch of Tik Tok's "Intangible Heritage Partner" programme in 2019, "Qiao' s Handmade Leather Art" has been launched and selected as a support project. Qiao Xue (Tik Tok ID: Master Qiao, a leather carver) started posting videos on the Tik Tok, mainly showing the audience the process of making leather art, displaying new bags, and answering questions. The account has over 670,000 followers and has posted nearly 320 works. At the same time, Qiao Xue opened a live stream every week for sales, and in less than a year, she had sold over 2 million RMB of leather products, with the highest turnover in a single session reaching 450,000 RMB.

On Tik Tok, the experiential value of intangible cultural heritage no longer relies on the value recognition brought by its level, but on the emotional, experiential value by producing novel and attractive videos and the functional experiential value by selling goods live.

As a platform-supported short video account, Master Qiao, a leather carving master, has been positioned for commercial value after being selected as an "African Heritage Partner". The "Qiao Family Handmade Leather Art" needs to produce relevant videos for dissemination and use the Tik Tok platform to live broadcast to achieve direct realisation, so that the cultural value is transformed into economic value. In network marketing, the value of handmade leather products is determined by the value of the consumer's functional experience, i.e., practicality, sales, customer satisfaction, etc. [12].

Although Qiaojia Handmade Leather Art is a municipal-level intangible cultural heritage, it is ahead of most national-level intangible cultural heritage in terms of commercial realisation, and its audience highly values its functional experience value. Qiaojia Handmade Leather Art's products are mainly women's leather bags, with prices ranging from RMB 1,0004,000. The design elements, patterns, and colours are more complex and vibrant, incorporating a lot of Chinese elements and modern design concepts, such as moose and puppies, which are more popular with contemporary women. Qiao Xue focuses on the production process and production details, not only conveying the message of high practical value of the bags to the public, but also highlighting the artistic collection value of the bags, giving the public a sense of 
'identity' with those bags, and making them aware of the time cost and cultural value of making the bags, thus increasing sales. Fans have commented positively on the appearance and quality of the bags, both in the comments section of the short video and in the live stream.

Nowadays, Master Qiao has several live broadcasts every week, interacting with fans in real time to show leather products and sharing her ideas to enhance the brand value. The ID of Qiao has a high frequency of live broadcasts, at least three times a week, which increases the brand's exposure and gives the audience more opportunities to get in touch with Qiao. She repeatedly emphasises that she is an inheritor of intangible cultural heritage to trust her for the first time.

\section{EMOTIONAL EXPERIENCE VALUE: MIAO SILVER JEWELRY MANUAL FORGING TECHNIQUE}

Miao silver decorations are the favorite traditional decorations of the Miao ethnic minorities, mainly used by Miao women to decorate themselves. It is a symbol of the Miao people's worship of nature and romantic aesthetics, the carrier of the social and historical memory of the Miao nationality, and the emblem of the Miao culture. Miao silver decorations are represented by-products from Leishan County, Guizhou Province, and Fenghuang County, Hunan Province. Silversmiths in Leishan County are mainly concentrated in Kongbai Village, Maliao Village and Wugao Village in Xijiang Town. Miao silver jewelry manual forging technique was selected as China's national intangible cultural heritage in 2006, which belongs to the category of traditional skills. Pan Shixue is one of the inheritors of Miao silver jewelry manual forging technique in Maliao Village, Xijiang Town, Leishan County, Guizhou Province.

Since 2018, Pan has been widely known by the public mainly by posting videos to show the craft and design of silver jewelry manufacturing and through the interactive way of responding to netizens' questions in the comment area. In the video, he showed the material, specific production process, special craftsmanship, daily using and maintenance methods of silver jewelry, original design combined with modern trends and traditional culture, clothing culture with ethnic minority characteristics, and so on. He also showed many stories about the origin of the above content, local natural scenery, and living conditions. In addition, combined with China's modern consumption habits, he carried out custom designs according to the wishes of customers on WeChat, which his works often have both practical and aesthetic value.

The skills and craftsmanship shown in the video amazed many consumers, who praised it as lifelike and brilliant. For example, a silver hat made by Miao sliver was once exhibited, which is the primary traditional headdress of Miao women. It consists of as few as 150 pieces of silver and up to more than 200 pieces of silver. The silver pieces are thin and delicate, and their patterns are amazing and flexible as if they have their own souls. Each work shows the artistry and charm of the Miao silver jewelry manual forging technique. In addition, as there are many kinds of silver decorations of the Miao nationality, there are corresponding decorations almost everywhere in the body, which can reflect the overall and perfect decorative visual effect. To a large extent, these meet the needs of consumers' aesthetic experience.

Miao silver jewellery manual forging technique has a long history and has experienced the evolution from primitive decorations to rock and shell decorations, from plant and flower decorations to gold and silver decorations. Later, the pattern and form were basically finalized. Only the variety of style was still being renovated, and the resulting jewelry chain became one of the symbols of the social evolution of the Miao nationality [13]. Many silver decorations contain warm and beautiful meanings, such as silverfish bracelets imply many children and grandchildren. Relying on Tik Tok, a new media platform, these videos make many people who do not know or understand them to understand or even fall in love with the Miao silver jewelry forging technique and Miao characteristic culture. For example, after knowing that "butterfly is the ancestor of the Miao nationality", many people bought and customized "Mother Butterfly" related products, which greatly promoted the cultural value identity of consumers.

The video posted on Tik Tok has attracted a large number of migrant workers to return to work in their hometown and many people who want to become apprentices to learn the skill. In addition, new models featuring craft experience, technique inheritance and cultural sales carried out by Tik Tok, such as the parentchild experience course shown in the video, enhance consumers' experience and recognition of the traditional handmade silver jewelry culture while meeting the functional experience needs of consumers, and promoting more people to understand the charm of Miao silver jewelry. Coupled with establishing the country's first silver jewelry and embroidery craft school, the inheritance and development of Miao silver jewelry forging technique have a stronger foundation.

Miao silver jewelry is second to none in the jewelry of all ethnic groups. On national festivals and marriage days, Miao Village has become a world of silver. One what they pursue is aesthetic appreciation, and the other is to show wealth and avoid evil spirits. This is the unique silver culture of the Miao Villages. The beautiful scenery, silver jewelry forging technique, and culture shown in the video have attracted a large number of 
tourists to come here for sightseeing and consumption and are quickly integrated into the traditional activities of Miao people in toasting and dancing. This recognition of the value of the Miao silver forging technique and its culture has promoted local tourism and the consumption of local tourism culture.

\section{CONCLUSION}

This paper mainly uses case studies, supplemented by a questionnaire to discuss the experience value of traditional handicrafts brought to the public by current media communication. Three cases are handmade leather art of family Qiao, silverware forging skills of Miao nationality, and bronze carving skill. Through these three typical examples, the audience can probably gain various kinds of experience value based on different layers, such as the aesthetic experience value, emotional value, functional value, and cultural identity value.

To sum up the three cases, the aesthetic experience value is based on the beauty of the video images on the one hand and the exquisiteness of the cultural product itself on the other. The emotional experience value is mainly built from the stories told in the video, the local customs, and the experiences of the inheritors themselves. The video can give the audience emotional resonance and establish an emotional connection. The functional experience value focuses on the practicality of the product or skill itself. Functional experience value focuses on the practicality of the products or skills, such as bags, accessories, and other practical items, in addition to the scope of application of the skill; value identity focuses on the consumer's recognition of the cultural and historical value of traditional skill.

As a medium based on visual and auditory communication, the new media platform is more conducive to establishing experiential values for audiences of the intangible cultural heritage skills. What's more, the audience's perception of the status and contribution of the culture to traditional Chinese culture is the most important thing that needs to be considered in the long term in the dissemination of traditional culture.

\section{REFERENCES}

[1] Liu, H,Theory of Mass Communication: Paradigms and Schools, Beijing: China Renmin University Press, 2008. [1]Liu Guangyu \& Wang Chengli, Research on the creation and dissemination of intangible cultural heritage images in the context of short video, Contemporary TV, 2021(02), pp.9598.

[2] Su Chang, Thoughts on the transmission of intangible cultural heritage short video in $5 \mathrm{~g}$ Era,
Journal of North Minzu University, 2021(03), pp.57-63.

[3] $\mathrm{Hu}$ Xiaotong, Innovation of short video on the dissemination of intangible cultural heritage, News world, 2020(07), pp.81-84.

[4] Wu Feng \& Song Shuaihua, Development characteristics and trend prospect of short video industry in 2020, Editorial Friend, 2021(02), pp.5358 .

[5] Xu Linyun \& Zhan Qian, Research on cross-cultural communication strategy of intangible cultural heritage short video, News Forum, 2021, 35(02), pp.56-58.

[6] Bai Changhong, Western customer value research and its practical enlightenment, Nankai Business Review, 2001(2), pp.51-55.

[7] Li Zhen, How do Internet platforms create experience value, Journal of Guangdong University of Finance \& Economics, 2017, 32(02), pp.15-30.

[8] Mathwickc, Malhotran, Rigdon E., Experiential value: conceptualization, measurement and application in the catalog and in-ternet shopping environment, Journal of Retailing, 2001, 77(1), pp.39-56.

[9] Li Jiangmin \& Wang Qing, Living inheritance of intangible cultural heritage, Tourism Tribune, 2020, 35(11), pp.78-89.

[10] Mei Na \& Chen Na, Research on the mode of short video on Tiktok for Intangible cultural heritage transmission, Press Outpost, 2019(05), pp.28-29.

[11] Zeng Mengyu, On the living inheritance strategy of intangible cultural heritage of traditional handcraft skills, Reform \& Openning, 2020, 1(02), pp.75-79.

[12] Xu Linyun \& Zhan Qian, Research on crosscultural communication strategy of intangible cultural heritage short video, News Forum, 2021, 35(02), pp.56-58.

[13] Bu Chaoqun \& Qiao Hongbo, Research on silver forging technology and its value of Miao Nationality in Leishan County, Cultural industry, 2020 (18), pp.82-85. 